\title{
El Procedimiento Acelerado de Refinanciación Concursal (PARC): Análisis preliminar en torno a una posible prórroga $a^{(*)(* *)}$
}

\author{
Fast-Track Insolvency Refinancing Procedure (PARC): preliminary analysis \\ regarding a possible extension
}

\author{
Sol Ivanna Aragón Samanez ${ }^{(* * *)}$ \\ Pontificia Universidad Católica del Perú (Lima, Perú) \\ Nicole Alexandra Sierra Roque ${ }^{(* * *)}$ \\ Pontificia Universidad Católica del Perú (Lima, Perú) \\ Milagros Alexandra Condezo Trinidad( ${ }^{(* * * * *)}$ \\ Pontificia Universidad Católica del Perú (Lima, Perú)
}

\begin{abstract}
Resumen: La creación del Procedimiento Acelerado de Refinanciación Concursal (PARC) no ha sido fortuita. Ante una crisis sanitaria mundial, el Gobierno peruano no solo ha tenido que adoptar medidas excepcionales respecto al sector sanitario, sino también en referencia al sector empresarial. Es así que este procedimiento nace como una medida complementaria para refinanciar las obligaciones de las empresas afectadas por la pandemia del COVID-19 y evitar la quiebra de las mismas. Además, al presentarse como el primer procedimiento concursal enteramente virtual, y por desarrollarse en un período de tiempo menor en comparación a los dos procedimientos ya existentes en nuestro país, se convierte en el único con estas singulares características.

Debido a estos factores, el presente trabajo tratará de explicar por qué el PARC no solo debería cumplir su vigencia hasta el 31 de diciembre de 2020, sino que su continuidad post-pandemia es necesaria, pues, está fuera de dudas que la crisis económica tendrá efectos a largo plazo. No obstante, surgen una serie de cuestionamientos respecto a su necesidad en nuestro ordenamiento jurídico, principalmente por la similitud que mantiene con uno de los procedimientos concursales ya regulados por la Ley General del Sistema Concursal y otras "falencias" administrativas que serán desarrolladas a lo largo del texto.
\end{abstract}

$\left({ }^{*}\right) \quad$ Nota del Editor: Este artículo fue recibido el 13 de septiembre de 2020 y su publicación fue aprobada el 28 de noviembre de 2020.

$\left(^{* *}\right.$ El presente artículo fue realizado bajo la asesoría del Mg. Anthony Lizárraga Vera-Portocarrero, quien es abogado por la Pontificia Universidad Católica del Perú. Magíster en Finanzas y Derecho Corporativo por la Universidad EAN, además, cuenta con un Postgrado en Derecho por la Universidad Carlos III de Madrid. Ha sido docente del curso de Derecho Concursal de pregrado y posgrado en la Facultad de Derecho y Ciencias Políticas de la UNMSM. Asimismo, es autor del libro "La Ineficacia Concursal: Estudio doctrinario y jurisprudencial en el sistema concursal peruano". Miembro de INSOL International, International Insolvency Institute y the Younger Academics Network of Insolvency Law (YANIL). Asimismo, ha sido seleccionado como miembro del Next Generation Class IX (2020) por el International Insolvency Institute. Actualmente, es socio y director del área de Reestructuración Empresarial y Derecho Concursal del Estudio Muñiz, Olaya, Meléndez, Castro, Ono \& amp; Herrera abogados.

$\left.{ }^{(* *}\right)$ Alumna de octavo ciclo en la Facultad de Derecho de la Pontificia Universidad Católica del Perú (PUCP). Asistente de Cátedra del curso de Instituciones del Derecho Privado 2 en la misma casa de estudios. Miembro ordinaria de IUS ET VERITAS. ORCID: https:// orcid.org/0000-0003-3145-047X. Correo electrónico: aragon.sol@pucp.edu.pe

${ }^{* * * *}$ Alumna de octavo ciclo en la Facultad de Derecho de la Pontificia Universidad Católica del Perú (PUCP). Miembro ordinaria de IUS ET VERITAS. https://orcid.org/0000-0003-4594-514X. Correo electrónico: a20171971@pucp.edu.pe

$\left.{ }^{(* * * *}\right)$ Alumna de octavo ciclo en la Facultad de Derecho de la Pontificia Universidad Católica del Perú (PUCP). Miembro ordinaria de IUS ET VERITAS. https://orcid.org/0000-0001-8059-5216. Correo electrónico: mcondezo@pucp.edu.pe 
Palabras clave: Procedimiento Acelerado de Refinanciación Concursal (PARC) - Sistema concursal peruano - Crédito - Liquidez - Empresa- COVID-19 - Derecho Concursal - Sistema romanogermánico

Abstract: The arrival of the Fast-Track Insolvency Refinancing Procedure (PARC for its initials in spanish) was not fortuitous. In order to face the global health crisis, the Peruvian government not only has been taking exceptional actions related to the sanitary system, but also has been concerned about the businesses affected by the COVID-19 pandemic. Likewise, this procedure has been created as a complementary action, with the purpose of refinancing the obligations of the companies that suffered the effects of the pandemic. Furthermore, as the first entirely virtual fast- track procedure, and also because of its development in a shorter time compared to the other existing procedures in Perú, the PARC is unique.

Due to these advantages, this article will try to explain why the PARC should not only be valid until December 31st, 2020. The continuity of this procedure in the post-pandemic stage is necessary, since the economic crisis will doubtlessly have longterm effects. Nonetheless, different questions arise regarding the permanence of this procedure in our legal system. Among these, the main questions are related to the similarity of the PARC with the Preventive Bankruptcy Procedure and also some administrative "flaws". This will be analyzed throughout the text.

Key Words: Fast-Track Insolvency Refinancing Procedure (PARC) The Peruvian insolvency system- Credit - Liquidity - Company COVID-19 - Bankruptcy Law - Civil Law

\section{Introducción}

Dentro de un contexto global en donde la situación económica mundial se ha venido agravando a raíz de la aparición del virus del COVID-19, queda fuera de dudas que, en el Perú, uno de los sectores más afectados por las medidas que se han tomado para enfrentar la pandemia ha sido el sector empresarial. Y es que, basta dar una mirada a nuestro alrededor para observar las consecuencias que el cese de un sector que, por su naturaleza, nunca se detiene, ha traído: despidos masivos de los trabajadores de las grandes empresas, reconversión de los objetos sociales de estas, liquidación de grandes cadenas de retail y de pequeñas y medianas empresas familiares, etc.

Ante dicho escenario, y antes de que se agrave aún más la situación del sector empresarial, el Poder Ejecutivo emitió el pasado 11 de mayo el Decreto Legislativo 1511 mediante el cual se creó el nuevo Procedimiento Acelerado de Refinanciación Concursal (en adelante "PARC"), el cual entró efectivamente en vigencia el 8 de junio de este año con la aprobación y publicación de su respectivo reglamento(1).

Sin embargo, la aparición de este nuevo procedimiento, que se suma a los ya regulados por la Ley General del Sistema Concursal (en adelante "LGSC"), no solo se enfrenta con el desafío de luchar contra una situación que exige (urgentemente) mayor eficacia y celeridad; sino que, así como toda norma, el PARC debe probar la necesidad de su existencia; es decir, demostrar que se trata de un procedimiento con características suficientemente distintivas a los procedimientos ya existentes que fundamenten su necesidad. $Y$ es que, de demostrarse que los procedimientos concursales ordinario y preventivo bastan para poder hacer frente a la situación de crisis, su promulgación vendría a ser en vano $y$, peor aún, inservible a las necesidades actuales de las empresas.

En ese sentido, el objetivo del presente trabajo es responder si es que, en primer lugar, el PARC, efectivamente, contiene las herramientas necesarias para enfrentar, dentro del novedoso contexto, la crisis que viene afrontando el sector empresarial. Mientras que, por otro lado, se analizará si es que, además, este procedimiento contiene suficientes características distintivas como para poder sostener su necesidad frente a los procedimientos ya existentes.

Para tales efectos, iniciaremos el trabajo haciendo un breve análisis de la situación actual que atraviesan las empresas en el país, pues esta realidad es la que ha conllevado a que se promulgue y sostenga la necesidad del PARC. Seguidamente, como preámbulo al tema concursal, nos parece necesario hablar del tema del financiamiento empresarial, pues el sistema concursal puede utilizarse, únicamente, cuando existen supuestos en los que el deudor no puede hacer frente a las deudas que mantiene con sus acreedores a propósito de la obtención de créditos. Posteriormente, abordaremos el tema de los procedimientos concursales, primero desarrollando los dos procedimientos concursales regulados por la LGSC, para que luego podamos desarrollar al PARC a partir

(1) Promulgado mediante Decreto Supremo 102-2020-PCM, cuya entrada en vigencia fue el 08 de junio del 2020. 
de las similitudes y diferencias que mantienen con aquellos dos procedimientos. A partir de ello, también será conveniente analizar cómo es que la legislación comparada ha tomado medidas concursales para poder hacer frente a la crisis que también enfrentan.

Una vez analizadas todas las cuestiones anteriormente señaladas, tendremos suficientes elementos para poder responder las dos cuestiones planteadas párrafos atrás. En otras palabras, lo que podremos responder es si es que el hecho de que se haya promulgado un mecanismo tal como el PARC, el cual, en teoría, busca hacer frente a una situación de crisis, realmente ayuda a la situación actual, o, simplemente, forma parte de la lista de normas que le son al ordenamiento inservibles.

No obstante, antes de empezar con la redacción, debemos precisar en este punto que, en vista de que se trata de un procedimiento que es -relativamente- nuevo y, por ende, tiene poco tiempo desde su entrada en vigencia ${ }^{(2)}$, este trabajo es solo un primer análisis preliminar a dicha norma que espera servir a la comunidad académica a acercarse más a este nuevo procedimiento.

En vista de la novedad del tópico, se trata de una primera opinión que las autoras de este artículo tenemos a partir del presente análisis. Sin perjuicio de ello, alentamos a que, a futuro, se realicen más trabajos académicos que aborden el tema, pues, no se puede descartar que dichos estudios puedan servir a una futura mejora del mismo.

\section{La pandemia y la crisis del sector empresarial: Contextualización del problema}

El pasado 11 de marzo del 2020, la Organización Mundial de la Salud anunciaba que el COVID-19 calificaba como una pandemia. Ante una situación sin precedentes, las medidas tomadas por los gobiernos para mitigar los efectos de la enfermedad también son extraordinarias, generando estrategias de control de la pandemia y grandes cambios en las políticas públicas. Dentro de las medidas comunes ${ }^{(3)}$ están el aislamiento de las personas infectadas en centros de salud o sus respectivos hogares; la cuarentena, como restricción o limitación al desplazamiento; el distanciamiento social; y el
Estado de Emergencia, junto a una completa inmovilización.

Sin embargo, si bien es evidente que los efectos se han visto reflejados en una emergencia sanitaria mundial al poner en grave riesgo la vida de las personas, esta crisis no es la única. Además de colapsar el sistema de salud, la pandemia también ha puesto en peligro a la economía y las empresas. La economía política nos dice que las decisiones tomadas por el gobierno tienen incidencia en la economía y viceversa. Teniendo ello en cuenta, desde las medidas de confinamiento, las restricciones y los nuevos protocolos, hasta las medidas laborales (sea el trabajo remoto, vacaciones sin goce, suspensión perfecta o incluso el cese colectivo) y de cualquier otra índole, que hayan sido tomadas como respuesta a la pandemia, tienen un efecto en la economía, y por supuesto, en los agentes económicos.

Dentro de los indicios de una crisis económica encontramos el detrimento del Producto Bruto Interno (PBI), la pérdida de empleos, negocios que se ven obligados a cerrar, el incremento de los niveles de pobreza, entre otros (Heath, 2012, pp.1-5). El mismo Banco Mundial estimó una caída del PBI latinoamericano de un $5 \%$, advirtiendo que incluso el porcentaje podría ser mayor ${ }^{(4)}$. Basta con tener una mirada al panorama actual para confirmar varios de los indicios antes mencionados. Internamente, las restricciones de circulación han generado un cambio de intensidad en la actividad productiva y económica de determinados sectores, sean proveedores de bienes o servicios, como es el caso del sector educación, transporte, turismo, etcétera.

Siendo las cosas así, lo que ha venido sucediendo en ciertos sectores empresariales es que casi todo el conglomerado de actividades que conlleva la administración

(2) A la fecha en la que el presente artículo fue remitido para su publicación, apenas contaba poco más de dos meses de vigencia y solo uno de estos procedimientos fue iniciado por Indecopi.

(3) Entre las medidas tomadas en nuestro país se encuentran los Decretos Supremos que declaraban el Estado de Emergencia que impedían la movilización social. Entre ellos están 044-2020-PCM ampliado temporalmente mediante los Decretos Supremos 051-2020-PCM, 064-2020-PCM, 075-2020-PCM, 083-2020-PCM, 094-2020-PCM y 116-2020-PCM; y precisado o modificado por los Decretos Supremos 045-2020-PCM, 046-2020-PCM, 051-2020-PCM, 053-2020-PCM, 057-2020-PCM, 058-2020-PCM, 0612020-PCM, 063-2020-PCM, 064-2020-PCM, 068-2020-PCM, 072-2020-PCM, 083-2020-PCM, 094-2020-PCM, 110-2020-PCM, 116-2020-PCM y 117-2020-PCM. 
y funcionamiento de una empresa, quedaron completamente estancados por las distintas medidas adoptadas por el Gobierno. Durante el camino de este abrupto proceso de adaptación a las nuevas condiciones, encontramos tres situaciones que aclaran el panorama. En primer lugar, están las empresas que han tenido que cesar completamente sus actividades. En segundo lugar, las que se han quedado a medio camino y están estancadas en su proceso de adaptación y recomposición (no pueden iniciar actividades por la dificultad que tienen para adaptarse a los protocolos que se han establecido para que puedan iniciarlas). Finalmente, se encuentra un reducido porcentaje de empresas que, si bien sí se han podido adaptar, lo han hecho a grandes costos.

Las empresas no solo han tenido que hacer grandes esfuerzos para lograr atravesar la transición de un escenario anterior a la pandemia a un escenario que se ha denominado como "nueva realidad", sino que, el mayor problema que se deriva de todo el contexto es que las empresas han visto sus ingresos sumamente afectados. En el marco de dicha situación, lo que sucede actualmente es que un gran número de empresas ven imposibilitada su capacidad de hacer frente a las deudas que mantienen con sus acreedores. Es decir, las empresas se encuentran en una situación de iliquidez, en la cual se ve gravemente afectada "la capacidad de pago de las obligaciones vencidas y exigibles más las que devendrán (...)" (López \& Nubia, 2018, p. 18).

\section{Financiamiento empresarial: El rol del crédito y las consecuencias de su incumplimiento}

El financiamiento empresarial es una de las formas comunes que utilizan los empresarios para desarrollar actividad empresarial. Los mecanismos "permiten a una empresa contar con los recursos financieros necesarios para el cumplimiento de sus objetivos de creación, desarrollo, posicionamiento y consolidación empresarial" (Rodríguez, 2012, p. 109). Estos a su vez exigen que, quien los solicite, cumpla con pagar la deuda por la cual los adquirió de acuerdo a los términos y condiciones de cada contrato.

En el ámbito económico, es esencial que una empresa tenga una estructura de financiamiento ${ }^{(5)}$. Asimismo, los mecanismos de financiamiento que provienen los agentes superavitarios (prestamistas) pueden ser utilizados cuando la empresa se encuentra en una situación de completa iliquidez para realizar sus actividades como también cuando un empresario no desee usar su capital. Los agentes económicos superavitarios son aquellos que no realizan un consumo total de sus ingresos generando así excedente (más ingresos que gastos) también llamado superávit. Por otro lado, en materia económica también existe el agente deficitario quien tiene más gastos que ingresos ocasionando su falta de capital o no tiene la suficiente o si la tiene, no desea utilizarla.

En el año 2018, se registró que en el Perú existen 2'393,033 empresas(6). Lamentablemente, en la actualidad, muchas de estas han detenido el curso normal de sus actividades y, por ende, no han podido obtener los ingresos que en una situación normal habrían obtenido. Esto ha derivado en dos situaciones. Por un lado, nos encontramos con que muchas empresas no pueden cumplir con obligaciones que previamente a la pandemia habían contraído con diferentes agentes superavitarios. Por otro lado, están las empresas que, para asegurar su existencia en el contexto actual han accedido a algún mecanismo de financiamiento empresarial. Uno de ellos es el crédito, el cual es uno de los principales medios que permite acceder a capital para financiar la actividad comercial.

\subsection{El rol del crédito como principal mecanismo de financiamiento empresarial Debemos precisar que, el término "crédito" proviene del latín "crēdere", que en su forma verbal infinitiva significa "creer". Este no}

(4) Véase https://www.bbc.com/mundo/noticias-52495362

(5) Por un lado, el Teorema de Modigliani \& Miller define la estructura sobre la base de la relación deuda/capital de la misma, es decir, se analiza el costo de la deuda sobre el costo del capital. Así, cuando el primero es menor que el segundo, las empresas optarán por el financiamiento, pues, al no existir deuda, el valor de la empresa se repartirá entre los accionistas y el Estado (impuestos). En cambio, en una empresa financiada, su valor se dividirá entre los accionistas, inversores (acreedores) y el Estado, pero en menor medida por los impuestos que sirven de escudo fiscal (Modigliani \& Miller, 1958, pp. 261-297, citado de Lizárraga, 2016, p. 328).

(6) Estas unidades empresariales están conformadas en un $94,9 \%$ por microempresas, un $4,2 \%$ por pequeñas empresas, un $0,6 \%$ por la gran y mediana empresa y un $0,3 \%$ por empresas que pertenecen a la administración pública (INEI, 2018). Como se observa, la actividad empresarial es desarrollada en un $99,1 \%$ por las micro y pequeñas empresas (MYPE). Es claro entonces que, por consiguiente, estas ocupan un lugar relevante en la estructura económica del país, pues generan "empleos en los distintos sectores de la economía; destacando, sobre todo, el sector agropecuario y el sector de servicios y comercio" (Mares, 2013, p. 2). 
consiste solo en un cambio de bienes, sino que tiene como base una promesa que vincula a las partes, en tanto esta debe cumplirse. Por ello es que, cuando hablamos de crédito, hablamos de confianza en esta promesa. Un ejemplo común sería la promesa de devolver una suma de dinero con un interés adicional. Teniendo en cuenta que el crédito implica confianza, y que esta no puede ser unilateral, sino que esta se forja al relacionarse con otras personas, la "reputación" que posee un sujeto también es relevante.

Aquel que muestra una imagen de solvencia (y que la tiene) es confiable para acceder a un crédito, puesto a que existen menores riesgos de incumplimiento de pago. Sucede lo contrario ante la insolvencia, donde hay mayores riesgos y menor confianza, por lo que el acceso al crédito puede complicarse. Entonces, tenemos que a más cualidades que generen confianza en el acreedor, mayor posibilidad de que este nos confíe (valga la redundancia) un capital o monto específico.

Si nos centramos en el ámbito empresarial, el crédito es de vital importancia. La Superintendencia de Banca, Seguros y AFP (SBS) presenta una clasificación de ocho tipos de créditos $^{(7)}$, los cuales podrían agruparse en créditos comerciales (corporativos, a grandes empresas, a medianas empresas, a pequeñas empresas y a microempresas), créditos de consumo (revolventes y no revolventes) y créditos hipotecarios.

Cuando hablamos de financiamiento empresarial, nos referimos principalmente a los créditos comerciales. Mediante el crédito, las compañías pueden gozar de mayor liquidez para obtener recursos, pagar servicios, proveedores, refinanciar deudas, cubrir el capital de trabajo, entre otros, siendo una de las fuentes de financiamiento empresariales indispensables.

Ante la pandemia que estamos viviendo, el papel de los bancos y entidades financieras es vital, ello debido a que en sus manos se encuentra asegurar la estabilidad del sistema financiero, y por lo tanto, la liquidez de las empresas y la no interrupción de la cadena de pagos. Entonces, el papel de estas entidades como principales acreedoras es sumamente importante, ya que, de generarse complicaciones en el sistema financiero, estaríamos ante una crisis peligrosa. El economista Juan Torres (2012) señala:

Una crisis financiera es una perturbación más o menos repentina que produce una pérdida considerable de valor en instituciones o activos financieros que tienen influencia decisiva en la marcha de los negocios y de la actividad financiera y económica general y que provoca un desequilibrio fundamental entre la demanda de medios de financiación que realizan los sujetos económicos y la oferta que hacen las entidades o intermediarios financieros (p. 2).
Si bien, como se ha mencionado anteriormente, la pandemia y las medidas necesarias para evitar el incremento de contagios han desacelerado la economía, esta situación no se ha expandido al sector financiero de la misma forma. En un contexto de pandemia, una crisis financiera sumada a la empresarial empeoraría aún más la situación actual de las empresas:

(...) en un contexto de crisis empresarial son múltiples las razones que cabe traer a colación a fin de justificar la dificultad de encontrar financiación externa adecuada y suficiente, no obstante, siendo así, una de estas razones resulta especialmente constatable: si el propio empresario o el círculo de las personas próximas al mismo ya no confían en el proyecto empresarial, ¿quién o quiénes van a confiar para realizar nuevos ingresos de tesorería en un momento tan delicado? (...) (Guasch, 2015, p. 166).

Tenemos entonces que, el papel del otorgamiento de los créditos es fundamental en el ámbito empresarial, y con mucho más énfasis en estos tiempos. Volviendo a la confianza, para ayudar a forjarla, es importante que los deudores cumplan con sus obligaciones. El cumplimiento oportuno de las obligaciones que tienen los deudores no solo les genera confianza, una buena calificación crediticia, reputación empresarial y credibilidad frente a sus demás acreedores, sino que mantiene el orden del sistema financiero. Por ello, tan importante como los créditos y el papel de los acreedores del sistema financiero, que benefician a las empresas, es que estas obligaciones no sean incumplidas.

Si aplicamos el principio de universalidad de Kant, no sería permisible ni ético admitir que todos los deudores del mundo dejen impagas sus obligaciones. En primer lugar, puesto que los acreedores no recuperarían ni el monto de préstamo, ni los intereses, generándoles pérdidas que podría llevarlos a la insolvencia si estas no son cubiertas a tiempo, o no tener capacidad para generar créditos. En segundo lugar, porque las condiciones de acceso al crédito serían más rígidas.

(7) Véase https://intranet2.sbs.gob.pe/estadistica/financiera/2015/Setiembre/SF-0002-se2015.PDF 
Las consecuencias se dan, entonces, tanto para acreedores, deudores y la sociedad, ya que, todo aquel que necesite liquidez ya no podrá obtenerla con la misma facilidad anterior al incumplimiento, y sus proyectos de emprendimiento caerán. Asimismo, se generaría una ruptura en la cadena de pagos, donde las empresas no podrían pagarles a sus proveedores, estos no podrían pagarles a sus trabajadores, y los últimos tampoco podrían cubrir sus gastos, deudas y necesidades, afectando la economía familiar. Se convertiría en una especie de caos del circuito económico, donde todos sus agentes se ven afectados de alguna forma.

Ciertamente se ha planteado un caso límite, pero nos ayuda a comprender mejor el importante rol de los acreedores, del crédito y de su cumplimiento, para evitar que el sistema financiero y la economía se conviertan en un caos. Por ello, el siguiente punto abordará a más detalle las consecuencias del incumplimiento.

\subsection{El incumplimiento del crédito como preámbulo al sistema concursal}

La empresa, como unidad básica de explotación económica, se encuentra encargada de satisfacer las diversas necesidades del mercado mediante la utilización de recursos materiales y humanos. Es así que está conformada por tres elementos indispensables para su creación y funcionamiento: capital, trabajo y recursos materiales (Rodríguez, 2012, p. 109). Respecto al primer elemento, debemos entender que, sin este, la empresa no podría funcionar; es decir, no podría iniciar, ni cumplir con las actividades económicas que se proponga, pues el capital es un elemento indispensable para que la empresa pueda ingresar y desenvolverse en cualquier mercado. Entonces, siendo un elemento indispensable, el empresario debe acudir a los distintos tipos de financiación que en el apartado anterior señalamos.

No obstante, nos concentraremos en qué es lo que sucede cuando al empresario se le hace imposible responder a las deudas que mantiene frente terceros, pues es con estos con los que-usualmente- hay vinculaciones jurídicas (por ejemplo, por medio de contratos) en los que el ordenamiento puede actuar para dar una respuesta a sus acreedores. $Y$ es que, si como sucede frecuentemente, hay acreedores que buscan el pago de su crédito, el ordenamiento es el que debe poder darnos luces a lo que deben hacer.

Para tales efectos, el ordenamiento ofrece una serie de herramientas que, ante los incumplimientos del deudor, el acreedor puede desplegar. Entre ellas, podemos encontrar a las ejecuciones del patrimonio, las medidas cautelares, la incautación de bienes, entre otras. Todas ellas reguladas desde la lógica de las relaciones contractuales de los sujetos.

Sin embargo, puede darse el caso de que -excepcionalmentelos acreedores (o deudores) que cumplen con una serie de requisitos indispensables, puedan optar por la opción de acogerse al sistema concursal. Y es que esta posibilidad se debe a la prevalencia que el ordenamiento le otorga al crédito.

Conforme a lo anterior, cobra vital importancia hablar de los procedimientos concursales (tema que se desarrollará en el siguiente apartado); sin perjuicio de ello, es preciso señalar que conforme al artículo Il del Título Preliminar la LGSC, la finalidad señalada es "la protección del crédito, ya sea facilitando la negociación colectiva (...) o bien permitiendo la asignación eficiente del recurso concursal ante los acreedores, en el caso de liquidación" (Puelles, 2013, p. 39).

Esta finalidad se deduce de dos supuestos: El primero de ellos, tiene que ver con el hecho de que

El modelo económico peruano se adhiere a la idea del libre mercado y de la competencia como presupuesto para el desarrollo de la sociedad, sin perder algún ideal de equidad en la distribución de riqueza y en la generación de oportunidades de éxito para los actores sociales. Dentro de una economía como esta, es importante proteger al crédito, en tanto institución. Esto puede ser tanto más importante en países emergentes (...). En esos contextos, la legislación en general debe facilitar el amplio acceso al crédito y procurar crear un contexto ideal para que las tasas de interés aplicables a tales créditos sean razonables y asequibles (...) (Puelles, 2013, p. 38).

Con relación a lo anterior y como segundo supuesto, debemos pensar en que si ya de por sí son altos los costos de coordinación entre acreedores y deudores antes del estado de insolvencia, surgido este, la cuestión es más compleja y no deja de serlo, a pesar de contar con un primer compromiso de cumplimiento de obligaciones y buen perfil empresarial (Del Águila, 2015, p. 316). En otras palabras, en este supuesto la empresa no tiene tampoco el poder legal para compeler a los acreedores para estar de acuerdo con ella" (Scwhartz, 2002, p. 128).

En vista de ello, el siguiente apartado abordará de manera muy concreta al Sistema Concursal, pues, como ya mencionamos es un mecanismo que, excepcionalmente, nos ofrece el ordenamiento para garantizar el 
crédito. Además de ello, una breve introducción a los procesos concursales existentes, nos dará luces acerca de cuál es su importancia y cuánta es su necesidad dentro de nuestro ordenamiento.

\section{El sistema concursal peruano: Procedimiento Concursal Preventivo vs. Ordinario vs. el Procedimiento Acelerado de Refinanciación Concursal}

Desde la aparición de la primera Ley General de Quiebras (hace aproximadamente cien años) hasta la actualidad, se ha desarrollado un Sistema Concursal que ha ido adaptándose a las necesidades de las empresas y entidades de nuestro país. Tal ha sido el desarrollo y acierto que nuestro sistema concursal ha tenido, que -a pesar de que dista de ser perfecto y posea ciertas falencias- la doctrina lo ha caracterizado como un sistema más atractivo y ventajoso que la de los otros países ${ }^{(8)}$.

Algunas características que resaltan dentro nuestro sistema concursal (entre ellas, las derivadas de los principios que la rigen) son las de universalidad, proporcionalidad y colectividad (todos estos principios se encuentran especificados en el Título Preliminar de la LGSC). No obstante, una que merece especial mención es aquella de la cual se deriva que los procedimientos concursales, se tratan de procedimientos sui generis de doble naturaleza: privatista y administrativista. Es decir que, conforme a esta última se trata de un procedimiento desjudicializado, siendo Indecopi la autoridad administrativa encargada que ha venido regulando los procedimientos concursales desde 1992.

Sin perjuicio de lo anteriormente mencionado, la aparición del COVID-19 ha traído una serie de inconvenientes en materia de financiamiento para las empresas peruanas ${ }^{(9)}$. Tal es el punto de crisis y problemas desatados dentro del sector empresarial, que el gobierno, en vista de la situación de iliquidez e insolvencia en la que muchas de las empresas peruanas clamaban encontrarse, decidió crear el PARC, un procedimiento temporal y distinto a los otros ya regulados en la LGSC (el procedimiento ordinario y el preventivo), el cual tendría la finalidad de "poder proteger a la empresa, reprogramar sus obligaciones impagas, evitar su insolvencia, la pérdida de negocios y fuentes de empleo y, con ello, asegurar la recuperación del crédito y la continuidad en la cadena de pagos en la economía nacional a todo nivel"(10)
En ese sentido, para poder entender cuáles son las novedades que trae consigo el PARC, no basta con realizar un análisis a la propia norma, sino que es preciso compararlo con los dos procedimientos ya existentes, pues de dicha comparación, se desprenderá la respuesta planteada a un inicio del trabajo. $Y$ es que creemos que, una norma, para poder sustentar su eficacia, no solo debe ser coherente con el contexto dentro del cual se promulga, sino que también debe poder diferenciarse de los otros ya existentes, pues, de no hacerlo, su existencia sería en vano. El presente punto trata de demostrar ello.

\subsection{Procedimiento Concursal Ordinario} De acuerdo a las publicaciones de inicio de concursos realizadas en el Boletín Concursal del Indecopi del año 2019, el Procedimiento Concursal Ordinario (en adelante "PCO") es el más utilizado por las empresas que se acogen al sistema concursal. Esto se debe a que, se trata de un procedimiento, que puede ser iniciado por cualquiera de los sujetos concursales (acreedor o deudor). Además, cuenta con las características suficientes como para poder entrar a mediar directamente problemas de iliquidez y en caso haya una situación patrimonial seriamente afectada (Puelles, 2013, p. 50).

\subsection{1. ¿Cuándo y quién lo solicita?}

Por la propia naturaleza de este sistema y bajo ciertas condiciones, hay dos sujetos posibilitados a promover el PCO: El propio deudor o los acreedores de aquel(11). No obstante, hay ciertos requisitos específicos que tanto los deudores como los acreedores deben cumplir para que Indecopi proceda a validar el inicio del mismo.

Por un lado, respecto a los procedimientos concursales iniciados por los deudores, de acuerdo al artículo 24 de la LGSC, deben de cumplir al menos dos de los siguientes requisitos: "a) Que más de un tercio del total de sus obligaciones se encuentren vencidas

(8) Véase Ezcurra, H. (2018). La muerte del Sistema Concursal. Revista de la Competencia y de la Propiedad Intelectual, 7(12), 157169.

(9) Este punto ha sido detallado en el apartado 2.

(10) Véase el artículo 1 del PARC.

(11) Véase el artículo 23 de la LGSC. 
e impagas por un período mayor a treinta días calendario; o b) Que tenga pérdidas acumuladas, deducidas las reservas, cuyo importe sea mayor al tercio del capital social pagado".

En cuanto a los procedimientos concursales que son impulsados por los acreedores del deudor, el artículo 26.1 establece: "Uno o varios acreedores impagos cuyos créditos exigibles se encuentren vencidos, no hayan sido pagados dentro de los treinta (30) días siguientes a su vencimiento y que, en conjunto, superen el equivalente a cincuenta (50) Unidades Impositivas Tributarias vigentes a la fecha de presentación, podrán solicitar el inicio del Procedimiento Concursal Ordinario de su deudor (...)".

\subsubsection{El reconocimiento de créditos}

Una vez firme la resolución de Indecopi que dispone la difusión del procedimiento, la Comisión de Procedimientos Concursales dispone de su publicación en el Boletín Concursal del Indecopi. En ella, se pretende el apersonamiento de los acreedores al concurso, con el fin de que soliciten el reconocimiento de sus respectivos créditos ${ }^{(12)}$.

Realizado el apersonamiento con la documentación correspondiente, Indecopi corroborará los datos y se pronunciará respecto a los acreedores que podrán formar parte de la Junta de Acreedores. Sin embargo, esto no significa que los acreedores que soliciten el reconocimiento tardío, no tengan derecho a cobrar su respectivo crédito, sino que no tendrán derecho a participar con voz y voto en la Junta de Acreedores ${ }^{(13)}$.

\subsubsection{Junta de Acreedores}

La Junta de Acreedores dentro de este procedimiento tiene dos facultades que tienen que ver con la permanencia o salida ordenada del deudor del mercado: (i) puede decidir o bien una reestructuración patrimonial o (ii) una disolución y liquidación.

De ser el caso que se decida una reestructuración, la Junta de Acreedores tiene una serie de atribuciones inéditas que no se repiten en los otros dos procedimientos ${ }^{(14)}$. Y es que esta puede decidir si el deudor puede mantener la administración, ser removido o administrar conjuntamente con un tercero (administración mixta). Asimismo, lo que se busca en esta etapa es aprobar el Plan de Reestructuración. Este incluiría un cronograma de pagos con las respectivas acciones que la empresa realizaría para poder cumplir con sus pagos.

En cuanto al caso de la disolución y liquidación, el liquidador será la persona encargada de realizar todos los activos del deudor y cancelar a los acreedores de acuerdo al orden de preferencia ${ }^{(15)}$. Por otro lado, la conclusión de la disolución y liquidación se da cuando: (i) el liquidador haya cancelado todos los créditos; (ii) cuando no haya activos con que pagar a los acreedores, donde el liquidador solicitará la quiebra judicial; o, (iii) no exista liquidador interesado en llevar un proceso de liquidación conducido por la autoridad concursal.

\subsubsection{Plazos procedimentales}

En cuanto al plazo procedimental estipulado para el PCO, se debe tomar en cuenta que no es posible determinar con exactitud el tiempo total que toma a los acreedores aprobar el instrumento concursal. Por ejemplo, los acreedores cuentan con cuarenta y cinco días hábiles para aprobar el destino del deudor y en caso de adoptar la reestructuración sesenta días hábiles para aprobar el plan y en una liquidación treinta para aprobar convenio. Sin embargo, no estamos contabilizando las impugnaciones de acuerdos de juntas o pedidos de nulidades que harían que los plazos sean más extensos sin una fecha determinada.

\subsection{Procedimiento Concursal Preventivo} El sistema concursal peruano, con la finalidad de generar un espacio adecuado a partir del cual se puedan asignar eficientemente los recursos respecto al patrimonio del deudor, como lo señala el artículo II del Título Preliminar de la LGSC, no solo ofrece un $\mathrm{PCO}$, sino también un procedimiento concursal preventivo (en adelante "PCP"). Este segundo tipo de procedimiento concursal busca evitar que el deudor se vea inmerso en una insolvencia mayor. Sus características se explicarán a continuación.

\subsection{1. ¿Cuándo y quién lo solicita?}

Según el artículo 103 de la LGSC, este procedimiento, a diferencia del ordinario, puede ser únicamente iniciado por el deudor. Ello se puede explicar principalmente por el interés del deudor en evitar un trágico panorama para su empresa antes de que sea demasiado tarde.

(12) Véase el artículo 32.2 de la LGSC.

(13) Véase el artículo 34. 1 de la LGSC.

(14) Véase el artículo 63 de la LGSC.

(15) Véase el artículo 42.1 de la LGSC. 
Asimismo, el artículo referido señala que es importante que, quien solicita el inicio de este procedimiento, no se encuentre en ninguno de los supuestos del artículo 24 de la misma norma. Estos supuestos son específicamente los que indican cuándo es factible recurrir a un procedimiento ordinario. En otras palabras, no es posible que una empresa con una situación calificada para un procedimiento ordinario pueda recurrir a uno preventivo.

\subsubsection{El reconocimiento de créditos}

El artículo 105 de la LGSC, que tiene la finalidad de señalar qué acreedores son aptos para participar de la Junta de Acreedores en un PCP, se remite a dos artículos de la misma norma. En su primer inciso se remite al artículo 34 inciso 1. En su segundo inciso, se remite al artículo 38. Puesto a que ambos artículos son aplicados también para el PCO.

\subsubsection{El rol de la Junta de Acreedores}

A diferencia del PCO, en el PCP el deudor ofrece una propuesta de refinanciamiento o un calendario de reprogramación de pagos, el cual se denominará Acuerdo Global de Refinanciación (en adelante "AGR"). Al ser preventivo, la Junta de Acreedores puede suscribir o no el AGR, pero no puede recurrir directamente a un PCO. El artículo 107 de la LGSC señala que es posible prorrogar la aprobación del AGR. Se entiende en tal situación que la Junta queda suspendida hasta la fecha acordada. El plazo máximo de suspensión es de 15 días después de que la Junta de Acreedores haya sido instalada.

De no suscribir el AGR, “(...) la Junta de Acreedores, siempre que representen más del $50 \%$ de los acreedores reconocidos o asistentes en la misma Junta que se desaprobó el AGR, podrá acordar su sometimiento al procedimiento concursal ordinario" (Lizárraga, 2020)(16) Además de ello, a diferencia de otros procedimientos, en el preventivo, la suspensión de la exigibilidad de las obligaciones es facultativa. Por ello, si no se aprueba el AGR y la Junta de Acreedores decide iniciar un procedimiento ordinario, el patrimonio del deudor sigue protegido y las obligaciones suspendidas hasta que se emita una resolución de inicio de procedimiento.

Asimismo, el artículo 106 señala los efectos una vez que el AGR es aprobado. El segundo inciso indica: "El Acuerdo Global de Refinanciación deberá contemplar necesariamente todos los créditos reconocidos, así como aquellos que sin haber sido verificados por la autoridad concursal se hubiesen devengado hasta la fecha de difusión del procedimiento, y será oponible a sus titulares para todos los efectos establecidos en la ley". El tercer inciso fija un porcentaje obligatorio de $30 \%$ a ser repartido en partes iguales a los acreedores laborales. De no fijar este porcentaje, el AGR es nulo.

\subsubsection{Plazos procedimentales}

Como se ha mencionado previamente, no existe un plazo específico de tiempo en el que todo PCO se desarrolle. De la misma forma sucede con los procedimientos preventivos, no existe un plazo homogéneo, puesto a que los procedimientos pueden extenderse en el tiempo debido a impugnaciones $u$ otros recursos. Sin embargo, la LGSC señala algunos plazos respecto de este procedimiento. Uno de los plazos ya señalados en el anterior punto es el de suspensión de la aprobación del AGR, de quince días como máximo ${ }^{(17)}$.

Asimismo, la LGSC contiene un artículo de suma importancia en su Título IV, referido exclusivamente al PCP. Este es el artículo 113 sobre aplicación complementaria de normas, que señala: "En todo lo no previsto en el presente Título será de aplicación las Normas Generales de la Ley, así como las disposiciones que regulan el Procedimiento Concursal Ordinario, en lo que resulte aplicable". En otras palabras, los plazos establecidos para el PCO pueden ser aplicados de forma supletoria en un procedimiento preventivo, tomando en cuenta los artículos 34 y 137.1.

\subsection{Procedimiento Acelerado de Refinanciación Concursal (PARC)}

La pandemia del coronavirus generó que gran parte de la actividad empresarial se vea reducida y paralizada en su totalidad. Así, muchas empresas nacionales, debido a las consecuencias económicas dadas -y por darse en el país-, corren el riesgo de salir del mercado al optar por disolver y liquidar la empresa.

Como ya hemos venido mencionado, para hacer frente a estos acontecimientos, el Poder Ejecutivo, el 11 de mayo de 2020, mediante Decreto Legislativo 1511, creó el PARC, un procedimiento concursal distinto al de los dos regulados en la LGSC analizados anteriormente, debido a que se caracteriza por su celeridad y por realizarse virtualmente. No obstante a que su promulgación se haya dado en may o, el PARC entró en vigencia con el

(16) Véase el artículo 109 de la LGSC.

(17) Véase el artículo 107 de la LGSC. 
Decreto Supremo 102-2020- PCM, que aprueba el Reglamento del PARC. Por consiguiente, las entidades calificadas podrían acogerse al PARC desde el lunes 8 de junio de 2020.

Finalmente respecto a lo general de este procedimiento, no se puede dejar de lado que el PARC tiene una vigencia que es temporal. $Y$ es que, en base al artículo 4 del Decreto Legislativo 1511 se menciona que "las entidades calificadas pueden acogerse al PARC hasta el 31 de diciembre de 2020". Por ende, luego de esa fecha en el ordenamiento peruano seguirá rigiendo solamente el PCO y el preventivo.

\subsection{1. ¿Cuándo y quién lo solicita?}

EI PARC puede ser solicitado e iniciado únicamente por las entidades calificadas (o deudoras) ${ }^{(18)}$ como las micro, pequeñas, medianas y grandes empresas. Sin embargo, "(...) no se encuentran comprendidas dentro del ámbito de aplicación las personas naturales, las sociedades conyugales o sucesiones indivisas, sociedades conyugales o sucesiones indivisas, sea que realicen o no actividad empresarial; así como, las entidades o patrimonios excluidos según el artículo 2 de la Ley General del Sistema Concursal"(19).

Quizá esta es una de las características que más polémica ha desatado respecto al PARC; y es que, desde nuestro punto de vista, no encontramos motivo suficiente por el cual las personas naturales sin importar si realizan o no actividad empresarial, sociedades conyugales o sucesiones indivisas no puedan acceder a este procedimiento. Más aún, parece incorrecta tomando en cuenta que el $73.6 \%$ de las empresas en el Perú se registran como personas naturales ${ }^{(20)}$. Debido ello, solo podría acceder al PARC un $26.4 \%$ de empresas con diferente organización jurídica. Esta situación da como resultado la desprotección a un gran número de empresas que, actualmente, se ven afectados por la pandemia y que, sin razón suficiente, se ven imposibilitados de acceder a un procedimiento que podría ayudarlos a lidiar con la severa situación que enfrentan a causa de las diferentes medidas que se tomaron a consecuencia de la pandemia.

En cuanto a cuándo se puede iniciar el procedimiento, el artículo 5 del Reglamento del PARC establece cinco requisitos: (i) estar clasificada en el Sistema Financiero, en la categoría de "Normal" o "Con Problemas Potenciales"; (ii) no encontrarse sometida a un procedimiento concursal; (iii) no tener pérdidas acumuladas, deducidas las reservas, cuyo importe sea mayor al tercio del capital social pagado; (iv) no encontrarse en los supuestos de disolución establecidos en el artículo 407 de la Ley General de Sociedades ${ }^{(21)}$; y, (v) que el origen de la crisis se deba al impacto del COVID-19(22). En vista de ello, el PARC es un procedimiento excepcional permitido solo para los sujetos específicos que, ante la pandemia, hayan padecido de problemas económicos.

\subsubsection{El reconocimiento de créditos}

Tanto el artículo 8 del PARC, como del Reglamento del mismo, detallan el procedimiento del reconocimiento de créditos. En base a estos artículos, los terceros acreedores al procedimiento tienen un plazo máximo de diez días hábiles contados desde el día siguiente de realizada la publicación en el Boletín Concursal para apersonarse al procedimiento a fin de solicitar el reconocimiento de sus créditos, vencido el plazo se declara improcedente las solicitudes. Una crítica en este procedimiento, es el no reconocimiento de los créditos laborales y de consumo.

Al respecto, por el lado de los créditos laborales se sabe que, en la línea de orden de los otros procedimientos concursales, estos son los primeros en el orden de preferencia. Esto debido a que tienen reconocimiento constitucional al establecerse que "el pago de la remuneración y de los beneficios sociales del trabajador tiene prioridad sobre cualquier otra obligación del empleador". Asimismo, dentro de los créditos laborales también se incluyen el pago de los aportes al Sistema Privado de Pensiones o a los regímenes previsionales administrados por la Oficina de Normalización Previsional (ONP). Por otro lado, en cuanto al crédito de consumo, este se otorga a las personas naturales para atender el pago de bienes, servicios o gastos que no están relacionados con una actividad empresarial.

Respecto al artículo 8, podría pensarse que este podría vulnerar el principio de colectividad al no reconocer los créditos laborales ni de consumo. Sobre ello, Sonia

(18) Véase el artículo 3.1 del PARC.

(19) Véase el artículo 3.3 del PARC.

(20) Véase https://www.inei.gob.pe/media/MenuRecursivo/publicaciones_digitales/Est/Lib1703/libro.pdf

(21) Véase Artículo 407 del Código Civil.

(22) Véase https://Ipderecho.pe/necesario-procedimiento-acelerado-refinanciacion-concursal-analisis-comparativo-procedimientoconcursal-preventivo/ 
Alva menciona que la vulneración se da al no tener justificación para privar a estos acreedores al derecho a participar en la toma de decisiones, pues son los acreedores laborales quienes tienen mayores incentivos para la aprobación del PRE, si se toma en consideración la situación económica del país ${ }^{(23)}$.

Sin embargo, consideramos que lo anterior no es del todo cierto, ya que una característica del PARC es el tratamiento especial que les da a ambos créditos en base al artículo 10 del mismo. En este se detalla que "de los fondos o recursos que se destinen al año para el pago de los créditos, por lo menos un $40 \%$ de asigna en partes iguales al pago de obligaciones laborales adeudadas a los trabajadores (...) y un $10 \%$ se asigna en partes iguales al pago de obligaciones de acreedores titulares de créditos derivados de una relación de consumo con la Entidad Calificada".

Así, a pesar de no tomar participación los acreedores de créditos laborales y de consumo en la Junta de Acreedores, no se les deja sin protección, debido a que el PRE tiene la obligación de tomar en cuenta un cierto porcentaje de los fondos para el pago de los créditos al año. Del mismo modo, lo establecido por el PARC es adecuado si se quiere garantizar la celeridad de este procedimiento concursal, porque, con la inclusión de estos créditos, Indecopi tardaría una mayor cantidad de meses en el proceso de reconocimiento de créditos imposibilitando esto el tener un PRE célere para los agentes económicos.

Cabe señalar que los créditos contingentes tampoco son reconocidos, pero en caso se levante la contingencia de estos, luego de aprobado el PRE, son incorporados al cronograma de pagos según el orden de agrupación de acreedores prevista en el PRE como lo establece el inciso 1 del artículo 10 del Decreto Legislativo 1511. Luego del reconocimiento de créditos, sólo los acreedores reconocidos en este son los que integran la Junta de Acreedores. Estos cuentan con el derecho de voz y voto para la aprobación o desaprobación del PRE, instrumento concursal por aprobar en este Procedimiento.

\subsubsection{El rol de la Junta de Acreedores}

En comparación con el PCO y el PCP, la Junta de Acreedores en el PARC es realizada virtualmente en su totalidad y, en adición, contando con la participación de un notario público. Durante su realización, el único tema de agenda es la discusión sobre la aprobación o desaprobación del PRE. Asimismo, tiene una similitud con el PCP respecto a la instalación de la Junta, ya que la instalación de la junta, en ningún caso implica un desapoderamiento de la administración de la entidad calificada, ni la facultad de realizar un cambio en la administración de la Entidad(24).

No obstante, si bien es cierto que las reuniones de la Junta de Acreedores en los otros dos procedimientos también son virtuales (su implementación y formalidades, están regularizadas en base a la Directiva Nº01- 2020- DIRCORD-INDECOPI), estas se tratan de medidas temporales. Esto, en tanto que, una vez que culmine el periodo de virtualidad de dichos procedimientos (31 de diciembre del 2020), se espera que vuelvan a su modalidad presencial. Por el contrario el PARC, es un procedimiento que no puede desentenderse de la característica virtual.

En cuanto al PRE, debemos señalar que (i) se trata del mecanismo a través del cual la entidad calificada obtendrá el refinanciamiento de sus obligaciones económicas; (ii) posee carácter obligatorio tanto para la entidad calificada, como para sus acreedores sin importar si los votos para la aprobación del PRE fueron a favor o en contra; (iii) si un acreedor no realiza el trámite de reconocimiento de créditos en el plazo establecido, el PRE le seguiría siendo obligatorio y; (iv) el rechazo o aceptación del PRE culmina con el procedimiento concursal(25).

\subsubsection{Plazos procedimentales}

Un aproximado sobre el plazo procedimental dentro del PARC encuentra su base en el Reglamento del mismo. Así en este se señala que el procedimiento debe tener una duración sesenta y cinco días hábiles a la que se le podría sumar una posible extensión de treinta y nueve días más. Sin duda alguna, esta cantidad de días es sustancialmente menor si se le compara con los otros dos procedimientos concursales. Sin embargo, existe todavía un vacío respecto a algunas etapas del PARC que dan como resultado que este pueda extenderse más allá de lo señalado en su respectivo reglamento.

Así, si bien parece que los plazos en el PARC sí se encuentran previstos, realizando

(23) Véase https://www.enfoquederecho.com/2020/06/15/contribuye-el-procedimiento-acelerado-de-refinanciacion-concursal-parc-alcumplimiento-de-la-finalidad-del-sistema-concursal/

(24) Véase el artículo 9.5 del PARC.

(25) Véase el artículo 10 del PARC. 
un análisis de este, se llega a la conclusión de que no hay un plazo completamente certero. $Y$ es que, si se toma en consideración el tiempo transcurrido desde el inicio del concurso hasta la Junta en base al flujograma del Reglamento del PARC da como resultado sesenta y cinco días hábiles, en la práctica el plazo es un aproximado de once meses, pues no hay una exactitud de cuánto será la duración de la primera junta en este procedimiento. Asimismo, el plazo a tomar en cuenta en la totalidad del PARC debe ser aumentado si existe una prórroga de dicha Junta. No obstante, de todas formas, seguiría teniendo un plazo menor que los otros dos procedimientos.

Otro motivo por el cual no existe un plazo con exactitud es debido a la nulidad pedida del PRE. Si la entidad calificada realiza una impugnación de la PRE para declarar su nulidad a pesar que la Comisión resuelva esto en un plazo de diez días hábiles como lo señala el artículo 10.4 del Reglamento, aún existe una posibilidad de impugnar dentro de quince días hábiles. Si en la apelación se declara fundada la nulidad incluso en esta etapa se puede apelar dentro de quince días hábiles de acorde al artículo 10.5 del mismo.

Una vez vistas las características de los tres procedimientos concursales que actualmente se encuentran vigentes en nuestro ordenamiento, el apartado 5 se enfocará en analizar el PARC. Sin perjuicio de ello, para poder realizar un análisis adecuado y poder responder las interrogantes planteadas en un inicio del trabajo, será útil comparar este procedimiento con otras medidas adoptadas por distintos ordenamientos. Ello con la finalidad de entender que la magnitud de la crisis económica $\mathrm{y}$, además, para analizar qué tan adecuadas han sido las diferentes medidas adoptadas para afrontar tal situación.

\section{La respuesta concursal latinoamericana: medidas y acciones de Colombia y México}

Perú no es el único país que ha buscado mitigar los efectos de la crisis económica. Por ello, consideramos que es adecuado tener un panorama de las medidas tomadas por otros países, para así realizar una comparación con el PARC. En ese sentido, en las siguientes líneas, haremos mención especial a dos países latinoamericanos que han abordado de manera distinta la crisis desatada por la pandemia: Colombia y México.

Por un lado, se sabe que Colombia introdujo un nuevo procedimiento para flexibilizar el régimen de insolvencia y hacer frente a la crisis. Así, junto con nuestro país, fue uno de los primeros en incluir un régimen concursal especial, en atención a la desafortunada situación de las empresas y acreedores. No obstante, el sistema concursal colombiano se caracteriza por emplear, principalmente, los procesos judiciales ${ }^{(26)}$; en comparación, a nuestro sistema peruano que utiliza solo procedimientos administrativos. No hace falta señalar que el tiempo invertido en un proceso judicial es mayor al de un procedimiento administrativo, razón por la cual este país decidió crear un Procedimiento de Reorganización Abreviado(27). Los nuevos procedimientos se llevan a cabo en las Cámaras de Comercio de Colombia (en centros de conciliación y con apoyo de mediadores). Estos se caracterizan principalmente por desarrollarse en períodos de tiempo más cortos; sin embargo, a pesar de ello, los acuerdos deben ser validados judicialmente, a diferencia del PARC donde basta la aprobación del PRE.

Además de ello, se realizaron modificaciones al régimen de insolvencia vigente sobre procesos, donde prima la digitalización de documentos -un aspecto que Perú dista de desarrollar adecuadamente- $y$, en adición, se introdujo la negociación de emergencia de acuerdos de reorganización ${ }^{(28)}$. Notamos entonces que Colombia parece haber tomado medidas adecuadas al contexto, y que se desarrollan con menos falencias respecto a la virtualidad.

Por otro lado, en el otro extremo tenemos a México. Los procedimientos concursales mercantiles mexicanos se rigen bajo los procedimientos concursales mercantiles mexicanos se rigen bajo la Ley de Concursos Mercantiles (en adelante "LCM"), que data del año 2000. Una empresa en estado de insolvencia puede optar por el procedimiento concursal mercantil para reprogramar el pago de sus obligaciones y; así, lograr salvar a la

(26) Se debe tomar en cuenta que el sistema concursal colombiano es mixto; es decir, utiliza tanto los procesos judiciales como los administrativos. Estos procesos tienen base legislativa en la Ley 1116 del año 2006. Para mayor información. Véase https://www. sic.gov.co/recursos_user/documentos/normatividad/Ley_1116_2006.pdf

(27) La Superintendencia de Sociedades de Colombia (organismo técnico) emitió el reglamento de este nuevo procedimiento, que fue introducido al ordenamiento por la Ley 560 del 2020 para establecer medidas transitorias por la emergencia.

(28) Ambas medidas reguladas por las leyes 1116 del 2006 y 560 del 2020, respectivamente. 
empresa, o puede decidir la quiebra y liquidación ordenada de esta.

Así, el fin de las normas concursales mexicanas es la subsistencia de las empresas, dándoles protección a sus bienes y derechos antes que velar por los créditos de los acreedores. Esto debido a que las primeras dan subsistencia laboral a los ciudadanos y aporta beneficios a la economía. Teniendo esto en cuenta, cabe señalar que, la normativa del PARC va más en línea con las normas mexicanas a diferencia de las normas concursales peruanas del PCO y PCP que tienen como propósito proteger el crédito del acreedor.

En contraste con el uso del procedimiento concursal peruano, el uso de procedimientos de quiebra en México es encargado mediante un juez en virtud del artículo 7 de la LCM. Por tanto, no existe una entidad administrativa concursal mexicana (en nuestro caso es INDECOPI) para realizar el trámite. Sin embargo, una ventaja concursal mexicana a resaltar es el reconocimiento de procedimientos de insolvencia extranjeros con base en el artículo 281 de la LCM, procedimiento que no existe en Perú.

Ante la situación de emergencia dada producto del coronavirus, como sabemos, en Perú se implementó el PARC. Por otro lado, en México se realizó la iniciativa de reforma a la LCM para establecer un Régimen Concursal de Emergencia, que al cierre del presente trabajo; lamentablemente, sigue en debate. Este régimen permitiría a los comerciantes (en el caso peruano la Entidad Calificada) acceder a un procedimiento concursal "flexibilizado" y virtual en su totalidad.

Por todo lo mencionado, se puede observar que la base de la normativa concursal mexicana es diferente a la normativa concursal peruana en cuanto a la finalidad y el alcance de los procedimientos concursales en el estado de emergencia. Este último punto se da porque nuestros procedimientos concursales reconocidos en la LGSC por el momento pueden ser virtuales y; además, contamos con un nuevo procedimiento: el PARC, en aras de garantizar la celeridad y virtualidad en sí misma que está tratando de conseguir México con el Régimen Concursal de Emergencia.

Tomando en cuenta que las medidas adoptadas por el ordenamiento jurídico colombiano y mexicano se encuentran en extremos opuestos, parece ser que las medidas adoptadas por el Perú aparecen en medio de estas. Es decir, si bien coincidimos con que presenta algunas características de celeridad que Colombia también ha inclui do, aún presentamos ciertas falencias en otros aspectos (como la virtualización de expedientes). No obstante, tampoco podemos decir que nos encontramos en una situación de falta de regulación adecuada al contexto, como el caso de México. Ante ello, a primera vista, el PARC parece ser un procedimiento necesario; sin embargo, para poder demostrar ello, quedan pendientes ciertos puntos que serán desarrollados en el siguiente apartado.

\section{6. ¿EI PARC como solución a la crisis empresarial?: Apuntes en torno a su necesidad}

Ya hemos mencionado líneas arriba el contexto en el que el PARC surgió: uno de crisis y emergencia en ciertos sectores empresariales. No obstante, el hecho de que haya surgido con la finalidad de apoyar una situación sin precedente, no es motivo suficiente para poder alegar que era un procedimiento necesario. $Y$ es que, lo que además de ello se debe analizar es si es que se trata de un procedimiento que presenta, cuando menos, ciertas características, que lo diferencien de los otros procedimientos ya existentes.

Para tal efecto, a continuación se analizará si su existencia era realmente necesaria y, además, si consiste en un procedimiento idóneo para conseguir el fin que se propone. Para ello, trataremos de contraargumentar las principales críticas que se hacen en torno a este y, en adición se explicará cuál podría ser su utilidad, de darse el supuesto de que continúe en vigencia más allá del tiempo previsto.

\subsection{Críticas y contraargumentos a favor de la necesidad del PARC}

Se han venido formando una serie de críticas en contra del PARC. Sin embargo, consideramos que todas se reconducen a una sola: la escasez de acogimiento a este procedimiento presentado hasta la fecha ${ }^{(29)}$. $Y$ es que, dentro de esta escasez encontramos tres argumentos que tienen como común denominador tal característica: (i) la similitud del PARC con el PCP; (ii) la carencia de una directiva que establezca con claridad el procedimiento y el pago de los derechos administrativos (tasas) de los procedimientos administrativos al interior del PARC y; (iii)

(29) Fecha en la que se remitió el presente artículo a la Comisión de Publicaciones de IUS ET VERITAS- 13 de septiembre de 2020. 
el hecho de que, ante la situación actual, el Gobierno haya adoptado medidas de apoyo a las empresas (como el fondo Reactiva Perú), para poder hacer frente a los diferentes problemas que podrían enfrentar las MYPEs. No obstante, las diversas aristas de esta crítica se verán contraargumentadas en las siguientes líneas.

(i) La esencia del PARC y su similitud con el PCP

En cuanto a la primera arista, no podemos negar que en la zona de intersección del PCP y el PARC hay ciertas características comunes: ambas pueden iniciarse únicamente por los deudores, la administración recae sobre el deudor y ambas están en la imposibilidad de poder decidir más allá de los acuerdos de refinanciación. A pesar de ello, consideramos que hay tres características que nos permiten hablar del PARC como un procedimiento único y distinto: (i) la celeridad; (ii) la virtualidad; y (iii) la finalidad perseguida.

Con respecto a la celeridad, como se explicó en el punto 4.3.4., el plazo procedimental del PARC es un aproximado de sesenta y cinco días hábiles a comparación del PCP y PCO, que tienden a tener una larga duración en la aprobación de sus instrumentos concursales. Este procedimiento permite crear un PRE con el objetivo de refinanciar las obligaciones de las entidades calificadas en el menor tiempo posible. En ese sentido, se convierte en un procedimiento funcional ante la situación de crisis económica que afrontamos. Esto, debido a que se necesitan respuestas prontas con medidas adecuadas dadas por la junta de acreedores de la entidad para lograr la continuidad de los agentes económicos en el mercado y el cumplimiento de sus obligaciones.

Respecto a la virtualidad, propia del PARC, esta es importante debido a las medidas de inmovilización social y cierre temporal de las oficinas gubernamentales, entre ellas, las de las diversas sedes del Indecopi, organismo encargado de los procedimientos concursales. De esta forma, si bien se han permitido reuniones virtuales de las juntas de acreedores en los dos procedimientos concursales regulados por la LGSC, esta es una medida excepcional y con duración limitada (hasta el 31 de diciembre del 2020)(30). Por otro lado, el PARC seguiría siendo virtual en su totalidad, ya que facilitaría su acceso. Esta última, iría de la mano con la celeridad, pues al proceder virtualmente existe un ahorro de costos y tiempo tanto para la entidad calificada, como para sus acreedores y la propia autoridad concursal.

En cuanto a la finalidad, debemos mencionar que, esta es diferente en el PARC. Como ha sido mencionado, si bien entre los dos procedimientos regulados en la LGSC existen una serie de diferencias, ambos persiguen una misma finalidad: salvaguardar el crédito y, por consiguiente, se busca una protección a los acreedores (artículo II del Título Preliminar de la LGSC). Sin embargo, esta línea que ha venido persiguiendo nuestro sistema concursal desde hace ya varios años, parece que ha encontrado un cambio de sentido con la aparición del PARC.

En el caso del PARC, por lo contrario a los otros dos procedimientos, el objetivo que pretende perseguir parece distinto. Ello se debe a que en la definición de su objetivo se señala que dicha finalidad consiste en “(...) proteger a la empresa, reprogramar sus obligaciones impagas, evitar su insolvencia, la pérdida de negocios y fuentes de empleo y, con ello, asegurar la recuperación del crédito y la continuidad en la cadena de pagos en la economía nacional a todo nivel"(31).

Tal como puede suponerse con una lectura preliminar de este artículo, se podría entender que queda -hasta cierto punto- de lado la salvaguarda del crédito y entra a primar la protección de la empresa. Y es que, claro, esto tiene sentido tomando en cuenta el contexto en el cual surge este procedimiento. Sin embargo, sería un error verlo desde una perspectiva únicamente tradicionalista; es decir, desde una aproximación en la que prima la conservación de la empresa (Baird, 2005, pp. 11-12). Y es que, si bien es cierto que la conservación de la empresa ahora se encuentra como el norte de este procedimiento concursal, a priori, tampoco se puede descartar que se ha dejado la salvaguarda del crédito.

Ello lo creemos así, debido a que, si bien con las características propias del PARC (especialmente aquella que consiste en la celeridad) se beneficia el deudor, en el sentido de que no queda supeditado a las largas discusiones de la junta de acreedores que deciden su destino (como sucede en el caso de los dos procedimientos tradicionales), los acreedores también se ven beneficiados, al saber que, en un tiempo mucho más corto, tendrán certeza sobre cuándo verían satisfecho su derecho al crédito.

(30) Véase Directiva 001-2020-DIR-COD-INDECOPI.

(31) Véase el artículo 1 del Decreto Legislativo 1511 
(ii) La carencia de una directiva que establezca con claridad el procedimiento y el pago de los derechos administrativos (tasas) de los procedimientos administrativos al interior del PARC

Respecto a la falta de tasas del PARC, lo que sucede con la tramitación de los dos procedimientos concursales establecidos en la LGSC, es que deben efectuar un pago llamado tributo mediante las tasas por cada procedimiento administrativo dentro de los procedimientos concursales. Así, cabe resaltar que los montos a pagar por los derechos de tramitación se encuentran establecidos en el Texto Único de Procedimientos Administrativos (TUPA) del Indecopi.

No obstante, desde la habilitación del funcionamiento del PARC, no se ha establecido el monto a pagar por la solicitud de inicio del procedimiento, como por sus etapas, entre ellas, el procedimiento de reconocimiento de créditos. Entonces, existe una incongruencia entre su adaptación y las medidas tomadas para su uso. Por un lado, se crea un nuevo procedimiento concursal con límite temporal que ayude mediante un PRE a conservar en el mercado las empresas afectadas por la crisis. Por otro lado, la no existencia del monto sobre el tributo a pagar, genera cuestionamientos acerca de cómo una empresa puede acogerse al procedimiento sin tener conocimiento sobre la totalidad del costo a realizar en este ${ }^{(32)}$.

\section{(iii) Reactiva Perú como medida de apoyo empresarial}

Finalmente, en lo que respecta a las otras medidas que el Gobierno peruano adoptó para que las empresas puedan hacer frente a la situación crítica de este sector, se encuentra el Programa de Garantías del Gobierno Nacional "Reactiva Perú"(33). Este fue creado con la finalidad de "promover el financiamiento de la reposición de los fondos de capital de trabajo de las empresas que enfrentan pagos y obligaciones de corto plazo con sus trabajadores y proveedores de bienes y servicios, a efectos de asegurar la continuidad en la cadena de pagos en la economía nacional" (artículo 1 del Decreto Legislativo 1455).

Tal finalidad, a priori, no parece distar mucho de aquella descrita en el PARC. No obstante, consideramos que la finalidad no es lo único que podemos analizar al comparar estas dos medidas nacidas a partir de la crisis del sector empresarial. Por el contrario, es necesario realizar ciertas precisiones que, a simple vista, no podrían quedar claras.

Cuando el Decreto Legislativo 1511 se publicó en el diario oficial “El Peruano" y, posteriormente, se publicó su Reglamento
(Decreto Supremo 102-2020-PCM), se esperaba que un número importante de empresas se acojan al PARC para refinanciar las obligaciones con sus acreedores. Sin embargo, hasta el 13 de septiembre de $2020^{(34)}$, solo una empresa se ha acogido al PARC $^{(35)}$.

Esto nos ha mostrado la escasez de solicitudes presentadas para el acogimiento al PARC. Creemos que, hasta la fecha, el poco uso del PARC se debe principalmente a las diferentes medidas de apoyo dadas por el Gobierno peruano, las cuales han contado con mayor difusión a nivel nacional. Una de estas medidas de apoyo es el conocido programa Reactiva Perú (descrito anteriormente).

Para acceder a Reactiva Perú se requiere presentar la negación de tener alguna deuda en cobranza coactiva mayor a una (01) UIT, así como el Reporte Tributario para Terceros dado por la SUNAT. Ambos documentos son sencillos de obtener virtualmente para ser presentados a la entidad financiera deseada. Por otro lado, la solicitud de inicio del PARC, especificada en el artículo 6 de su Reglamento, menciona once puntos a cumplir para la admisibilidad de la solicitud. Entre estos requisitos, se encuentra la fecha del pago de la tasa por los derechos de tramitación (numeral k del artículo 6.1), monto que no ha sido especificado en el Reglamento o en la sección de Procedimientos Concursales de la página web del Indecopi ${ }^{(36)}$.

Por ello, si analizamos la situación de una empresa con problemas de liquidez, es clara su preferencia por la adopción del programa Reactiva Perú. Ello debido a que es más rápida la posible admisibilidad de acceder a este crédito, en comparación a acudir a un trámite como el PARC. Esto principalmente porque, si bien es un procedimiento célere frente a los otros dos procedimientos concursales del ordenamiento peruano, también podría verse

(32) Para efectos de la presente investigación, la autoridad concursal nos indicó mediante la Carta 001234- 2020- GEG- SAC/ INDECOPI que, a la fecha del cierre del presente trabajo, no hay tasas para la tramitación de algún procedimiento administrativo al interior del PARC.

(33) Promulgado mediante el Decreto Legislativo 1455 el pasado 29 de mayo del 2020

(34) Fecha en la que se remitió el artículo a la Comisión de Publicaciones de IUS ET VERITAS.

(35) Véase La Corporación Logística Maquinarias del Perú S.A.C.

(36) Véase https://www.indecopi.gob.pe/web/procedimientos-concursales/presentacion 
como "arriesgado", teniendo en consideración la inexactitud del monto de la tasa para el procedimiento de trámite.

A pesar de lo mencionado anteriormente, no podemos dejar de lado que el PARC es un procedimiento concursal que busca hacer frente a situaciones de insolvencia. Es decir, supuestos en los que la afectación del patrimonio es tal, que el deudor no puede afrontar las deudas que mantiene con sus acreedores. Por su parte, medidas como Reactiva Perú buscan ayudar con la liquidez de las empresas, lo cual implica que no deben existir niveles de insolvencia altos para acceder a esta garantía.

Sin embargo, este último por sí solo no puede ser tomado como un impulso para que las empresas puedan afrontar la crisis. Por ello, también es necesario adoptar medidas que puedan dar un espacio de tiempo en beneficio del deudor para el pago de sus obligaciones frente a los acreedores y evitar que la poca liquidez existente se desvanezca. Es en ese escenario donde los sistemas concursales con medidas de refinanciamiento coadyuvan a afrontar la crisis.

Siguiendo esa misma línea, a pesar de que existan mecanismos de financiación otorgados por el Gobierno peruano a favor de las empresas afectadas por el COVID-19, existe una necesidad de otorgar un procedimiento que pueda ayudar en la insolvencia y evitar la iliquidez. Dado que muchas empresas han solicitado préstamos derivados de Reactiva Perú y otros programas, el empresariado empezó a operar y honrar sus obligaciones. Sin embargo, si las empresas no han establecido un plan ordenado de pagos, los problemas de liquidez regresarán en un futuro inmediato. Por ello, consideramos que el PARC es un mecanismo complementario a los préstamos garantizados por el Estado y no excluyente, como está ocurriendo en la actualidad.

Las empresas deben invertir la liquidez obtenida en base a Reactiva Perú en capital de trabajo y mantener el negocio en marcha. Si bien, aún no se ha utilizado el PARC como fuente de refinanciamiento, creemos que ello, en un futuro no muy cercano, ocurrirá. Esto principalmente por la necesidad de refinanciar las deudas adquiridas que no pueden cubrir con Reactiva Perú, por lo que contemplamos que el plazo de duración de este procedimiento se deberá extender en el tiempo, lo cual será explicado en el siguiente punto.

\subsection{Necesidad de su permanencia post-pandemia}

A lo largo del presente texto se ha tratado de ilustrar cómo la pandemia ha tenido efectos negativos en la economía, y se ha resaltado específicamente el ámbito empresarial. Habiendo observado ello, y tomando en cuenta las características más beneficiosas que el PARC presenta en comparación a los otros dos procedimientos concursales existentes, creemos que es importante contemplar qué sucederá con este nuevo procedimiento y la posibilidad de que su vigencia pueda extenderse.

Como ha sido señalado, el Decreto Legislativo 1511 establece que el período de vigencia de este nuevo procedimiento culmina el 31 de diciembre del 2020. Hasta la fecha, habiendo transcurrido aproximadamente cuatro meses desde la entrada en vigor de la norma, se han presentado dos solicitudes de inicio de procedimiento, de las cuales una de ellas fue admitida ${ }^{(37)}$. Cabe preguntarnos entonces si es que existen razones suficientes por las cuales se debería extender el período de vigencia de este procedimiento, o si es que es posible que algunas de las características más favorables puedan ser acogidas.

Actualmente, nos encontramos en un contexto en el que probablemente la virtualidad no solo sea empleada de forma momentánea, sino que, al parecer, empezará a introducirse en el desarrollo de la vida jurídica. Incluso previamente a que la crisis sanitaria impactara al mundo, diferentes países habían puesto su mirada en la "virtualización", buscando que los procesos judiciales puedan modernizarse y facilitar ciertos trámites. Sin ir muy lejos, en nuestro país se implementaron mesas de partes virtuales en determinados procesos y procedimientos (como algunos llevados en Indecopi). Sin embargo, a pesar de los intentos por conectarnos con la tecnología, presentamos diversas fallas.

En relación con el PARC, esto puede notarse en el hecho de que la información que debe ser pública (como los expedientes de este nuevo procedimiento) aún no pueden ser consultados a través de la página web de Indecopi. A pesar de ello, la virtualización es esencial, puesto a que permite que una gran cantidad de acreedores puedan presentarse a la junta de acreedores, evitando un riesgo de contagio que sería mayor si es que esta fuera presencial (una de las razones por las que esta es necesaria actualmente). Así, si bien es cierto que tanto los procedimientos concursales ordinario y preventivo se han adaptado a un contexto virtual, sabemos que los fines de estos dos procedimientos son distintos, no responden al problema

(37) Véase Expediente 02-2020-PARC. 
de la insolvencia causada por el COVID y no cuentan con la flexibilidad de las medidas del PARC antes expuestas, como el acceso de las micro y pequeñas empresas.

En ese sentido, creemos que es necesario que este procedimiento continúe en vigencia no solo hasta el 31 de diciembre, sino también que pueda ser útil para el período postpandemia, el cual debería estar enfocado en la recuperación económica del país. Dentro de los factores que influyeron en que solo exista un único procedimiento PARC hasta el mes de septiembre se encuentran los diferentes programas de apoyo presentados por el Poder Ejecutivo, como Reactiva Perú. Los préstamos otorgados a las empresas por este programa cuentan con un período de gracia de 12 meses, y el plazo de préstamo es de 36 meses. Por lo tanto, si bien en la actualidad no se han presentado problemas de solvencia, es probable que luego de finalizar este año, cuando termine el período de gracia sí sean visibles.

Ello podría explicarse en que los ingresos de las empresas se han reducido considerablemente con el COVID-19, y que las deudas han aumentado. En adición a ello, se debe considerar que los intereses de los préstamos de Reactiva se capitalizan durante el período de pago, pues el período de gracia no implica quedar exento de los mismos. Entonces, si bien en la actualidad el PARC no ha sido utilizado de manera numerosa, es probable que, en los siguientes meses, los problemas de solvencia aparezcan con mayor intensidad.

Ante tal situación, el PARC será una herramienta útil, por lo que la autoridad concursal tendrá que estar lo suficientemente preparada, y tendrán que implementarse adecuadamente las plataformas virtuales por las que estos procedimientos se lleven a cabo. Asimismo, Indecopi debería tomar un rol más activo en la difusión de este procedimiento que trae muchas más ventajas que el ordinario y preventivo, cuyos plazos procedimentales son notoriamente mayores en la práctica, y que lamentablemente la administración no está dispuesta a modificar.

\section{Conclusiones y reflexiones finales}

La pandemia no solo ha sido trágica para la salud de las personas, poniendo en situaciones sumamente complicadas a los Estados respecto a sus sistemas de salud. Al mismo tiempo, como hemos descrito en este trabajo, se presentaron efectos en la economía que han sido también amplios y negativos. Entre ellos destacan la pérdida de empleos, negocios que se ven obligados a cerrar, acreedores que ven impagas las obligaciones en su favor, el incremento de los niveles de pobreza, entre otros.

Con esto no queremos dar a entender que las medidas de prevención sanitaria no eran imprescindibles, sino que buscamos resaltar el problema de las empresas, el cual no puede ser dejado de lado. Ante ello, el PARC se presenta como un procedimiento fast-track, el cual se hace necesario, tanto al evitar exponer al contagio a los participantes gracias a la virtualidad, como para evitar desenlaces que pongan a los actores en peores situaciones de insolvencia. Reafirmamos entonces que es necesario y será necesario en los próximos meses, hasta que podamos contar con una economía suficientemente recuperada.

Sin embargo, para poder analizar el PARC, señalamos que es necesario tomar en cuenta la importancia del crédito y del sistema financiero en el desarrollo de las actividades económicas de los emprendedores y en el ámbito empresarial peruano. Sabemos que es a partir de los créditos que estos actores económicos pueden contar con liquidez, la cual puede ser empleada para obtener recursos, pagar servicios, proveedores, refinanciar deudas, cubrir el capital de trabajo, entre otros, siendo una de las fuentes de financiamiento empresariales indispensables.

El incumplimiento de tales créditos implica (i) la pérdida de la confianza de sus acreedores, credibilidad crediticia y reputación empresarial; (ii) una posible desestabilización del sistema financiero; (iii) perjuicio hacia los acreedores, por el rompimiento de la cadena de pagos; y, por último, pero no menos importante, (iv) incrementar la rigidez del acceso al crédito. Además de ello, es a partir del incumplimiento que opera el Sistema Concursal como protección del crédito. Sin embargo, en un contexto de pandemia mundial - que no es razonablemente previsible por las empresas - Ios procedimientos tradicionales (PCO y PCP) no pueden ser las únicas opciones.

A partir de esta última premisa, es que el PARC nace como procedimiento concursal en un contexto sin precedentes. Así, la finalidad que el sistema concursal perseguía (la salvaguarda del crédito) dio un cambio con el PARC, pues ahora, si bien no se le quita total importancia al crédito, sí cobra importancia en la continuidad de la cadena de pagos; es decir, la continuidad de la empresa. Asimismo, de este procedimiento debemos resaltar el hecho de que se trata de un procedimiento 
mucho más veloz que los otros dos regulados; además de que es completamente virtual.

Sobre la legislación comparada, países como Colombia y México, los cuales se encuentran en polos opuestos, han coadyuvado a que podamos comparar qué tanto se ha desarrollado su sistema concursal durante la pandemia. Por un lado, existen características de la reforma del sistema concursal colombiano que podríamos tomar como ejemplo para mejorar la aplicación del PARC, como sería contar con una administración mejor preparada para desenvolverse en la virtualidad. Por otro lado, consideramos que México es un punto de referencia para notar que, en nuestro caso, si bien tenemos falencias, el Poder Ejecutivo adoptó rápidamente medidas en materia de insolvencia como una alternativa para enfrentar las crisis empresariales.

Sin perjuicio de que nuestro país se encuentra en un punto medio, como hemos señalado en el apartado 5.1, existe una crítica relacionada a la escasez de solicitudes para acogerse al procedimiento, la cual se divide en tres aristas: (i) la similitud entre el PARC con el PCP; (ii) la falta de tasas; y (iii) la preferencia por el programa Reactiva Perú. Entre los factores que más han influido en que exista poca acogida al PARC, se encuentra el programa Reactiva Perú, que otorga liquidez y funciona como una herramienta que impulsa el reflotamiento de las empresas. A pesar de ello, no se debe olvidar que Reactiva Perú debió ser considerada como una medida de apoyo a ser empleada en conjunto con el PARC y no de forma aislada.

En esa misma línea, los préstamos que otorga Reactiva Perú implican un período de gracia que no dura indefinidamente. Una vez cumplidos los doce meses de este periodo, los intereses se capitalizarán en el período de pago, pues el préstamo termina a los treinta y seis meses y los intereses no se exoneran. Como resultado de ello, las entidades calificadas al programa tendrán más presión para cumplir con obligaciones que en realidad superan sus capacidades de solvencia (considerando las pérdidas ocasionadas por la pandemia).

Por ello, creemos que el PARC no solo debe cumplir su vigencia hasta el 31 de diciembre, sino que esta debe ser prorrogada hasta que la crisis económica pueda verse disminuida. En ese sentido, se debería ampliar el plazo de vigencia, pues demostrará que es un mecanismo concursal esencial para dar soporte a los agentes económicos cuando persista la insolvencia. La prórroga del Decreto Legislativo 1511 será una respuesta a los numerosos casos PARC que se presentarán en el futuro, y actuará ante las situaciones de insolvencia.

Es así que, de acuerdo a ello, en estos meses, deberían implementarse y acondicionarse los aspectos faltantes, como el tributo a pagar por el procedimiento (tasas), el libre acceso a la información de los expedientes y la inversión en una adecuada difusión. En esa línea, no consideramos que añadir un nuevo procedimiento al sistema concursal peruano haya sido innecesario. Por el contrario, esta ha sido una medida necesaria en un contexto en el que tomar menos acción ante los problemas económicos y de solvencia antes explicados, implicaría acrecentar el nivel de crisis y no de protección . Así, el PARC es un plus para garantizar que menos empresas se vean envueltas en un escenario de quiebra y liquidación. En síntesis, el PARC fue necesario al empezar la crisis, es necesario en la actualidad y será necesario para la recuperación económica del país.

\section{Referencias bibliográficas}

Baird, D. (2002). Axiomas concursales aceptados. THEMIS-Revista de Derecho, 45, 7-24. http:// revistas.pucp.edu.pe/index.php/themis/article/ view/11870

Del Águila, P. (2015). El plan de reestructuración como instrumento de competencia en el mercado de empresas insolventes. Derecho PUCP, 74, 315-332. http://revistas.pucp.edu.pe/index.php/ derechopucp/article/view/13599

Guasch, R. (2015). La posición jurídica de los acreedores subordinados en la fase de convenio. En Estudios sobre el futuro Código Mercantil: libro homenaje al profesor Rafael Illescas Ortiz. (pp, 162-181). Universidad Carlos III de Madrid. http:// hdl.handle.net/10016/21078

Heath, J. (2012). Lo que indican los indicadores. INEGI México. http://www.economia.unam.mx/ academia/inae/pdf/inae4/u3I3.pdf

Jordà, O., Sighn, S., \& Taylor, A. (2020). La larga resaca económica de la pandemia. Finanzas \& Desarrollo, 57(2), 12-15. https://www.imf.org/ external/pubs/ft/fandd/spa/2020/06/pdf/fd0620s.pdf

Lizárraga, A. (2016). La implementación de un régimen especial para las MYPE. Derecho PUCP, 77, pp. 323-347. https://doi.org/10.18800/ derechopucp. 201602.013

Lizárraga, A. (2020, 23 junio). Las diferencias entre un procedimiento concursal preventivo $y$ un procedimiento concursal ordinario a propósito del caso LATAM. IUS 360. https://ius360.com/ derecho-concursal/las-diferencias-entre-unprocedimiento-concursal-preventivo-y-unprocedimiento-concursal-ordinario-a-propositodel-caso-latam-anthony-lizarraga/

López, M \& Nubia, A. (2018). Análisis multivariable de la iliquidez de las empresas tipo pymes del sector de la Construcción. Universidad Católica 


\section{Sol Ivanna Aragón Samanez \\ Nicole Alexandra Sierra Roque Milagros Alexandra Condezo Trinidad}

de Colombia. https://repository.ucatolica.edu.co/ handle/10983/16029

Mares, C. (2013). Las micro y pequeñas empresas (MYPE) en el Perú. Revista Jurídica Thomson Reuters. La Ley, 18, 1-20.

Puelles, L. (2013). Procedimientos Concursales. En Análisis de las funciones del Indecopi a la luz de las decisiones de sus órganos resolutivos: Colección por el vigésimo aniversario del Indecopi (pp. 35-64). Instituto Nacional de Defensa de la Competencia y de la Protección de la Propiedad Intelectual.

Rodríguez, M. (2012). Mecanismos de financiación empresarial en Colombia. Derecho y Realidad, 10(19), 107-116. https://revistas.uptc. edu.co/index.php/derecho_realidad/article/view/4878

Schwartz, A. (2002). Una aproximación contractual a la insolvencia empresarial. THEMIS-Revista De Derecho, 47, 119-147. http://revistas. pucp.edu.pe/index.php/themis/article/view/11874

Torres, J. (2012). Crisis Financiera. Universidad Nacional Autónoma de México. http://conceptos.sociales.unam.mx/conceptos_ final/504trabajo.pdf 


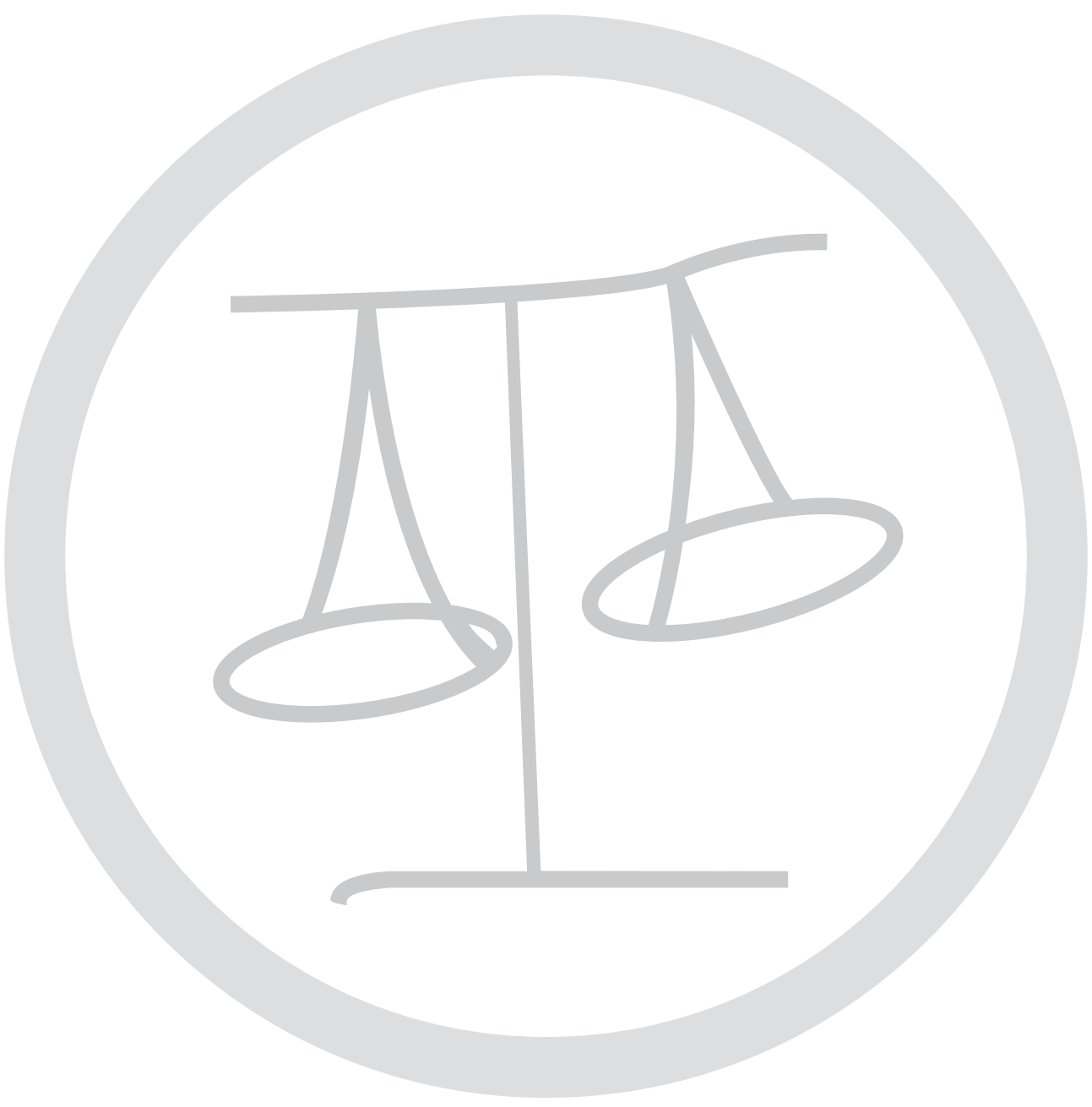

